\title{
Inter-laboratory comparison between NMIJ and KRISS of calibration capabilities for torque measuring devices in the range from $50 \mathrm{~N} \cdot \mathrm{m}$ to $2 \mathrm{kN} \cdot \mathrm{m}$
}

\author{
Koji Ogushi ${ }^{1}$, Atsuhiro Nishino ${ }^{1}$, Kazunaga Ueda ${ }^{1}$, Min-Seok Kim ${ }^{2}$ and Yon-Kyu Park ${ }^{2}$ \\ ${ }^{1}$ National Metrology Institute of Japan, AIST, Tsukuba Central 3, 1-1-1 Umezono, Tsukuba, Ibaraki, 305-8563, Japan \\ ${ }^{2}$ Korea Research Institute of Standards and Science, 267 Gajeong-Ro, Yuseong-Gu, Daejeon, 305-340, Rep. of Korea
}

\begin{abstract}
An inter-laboratory comparison of the calibration capability for torque measuring devices (TMDs) was conducted between the National Metrology Institute of Japan (NMIJ) in the National Institute of Advanced Industrial Science and Technology (AIST) and the Korea Research Institute of Standards and Science (KRISS). Three high-performance torque transducers having rated capacities of 100 $\mathrm{N} \cdot \mathrm{m}, 1 \mathrm{kN} \cdot \mathrm{m}$, and $2 \mathrm{kN} \cdot \mathrm{m}$, and a bridge calibration unit (BN100A) were used as the transfer devices. The $1 \mathrm{kN} \cdot \mathrm{m}$ and $2 \mathrm{kN} \cdot \mathrm{m}$ transducers had one bridge, but the $100 \mathrm{~N} \cdot \mathrm{m}$ transducer had two bridges that acquired data more reliably. An identical indicator/amplifier type (DMP40) owned by each laboratory was used. All of the transducers and BN100A were transferred from NMIJ to KRISS. For the comparison, NMIJ used $1 \mathrm{kN} \cdot \mathrm{m}$ and $20 \mathrm{kN} \cdot \mathrm{m}$ deadweight torque standard machines (TSMs), and KRISS used a $2 \mathrm{kN} \cdot \mathrm{m}$ deadweight TSM. In particular, the capability of the $1 \mathrm{kN} \cdot \mathrm{m}$ TSM at NMIJ was examined after some improvements. In the calibration range from $50 \mathrm{~N} \cdot \mathrm{m}$ to $2 \mathrm{kN} \cdot \mathrm{m}$, relative deviations were less than $3.0 \times 10^{-5}$ for increasing torques. Sufficiently small deviations were obtained between the calibration results in the two laboratories, as compared with their calibration and measurement capabilities (CMCs), which were $3.5 \times 10^{-5}$ for the $1 \mathrm{kN} \cdot \mathrm{m} \mathrm{TSM}$ at NMIJ, $7.0 \times 10^{-5}$ for the $20 \mathrm{kN} \cdot \mathrm{m}$ TSM at NMIJ, and $5.0 \times 10^{-5}$ for the $2 \mathrm{kN} \cdot \mathrm{m} \mathrm{TSM}$ at KRISS (as relative expanded uncertainties).
\end{abstract}

\section{Section: RESEARCH PAPER}

Keywords: torque standard machine; torque; comparison; transfer standard; bridge calibration unit

Citation: Koji Ogushi, Atsuhiro Nishino, Kazunaga Ueda, Min-Seok Kim and Yon-Kyu Park, Inter-laboratory comparison between NMIJ and KRISS of calibration capabilities for torque measuring devices in the range from $50 \mathrm{~N} \cdot \mathrm{m}$ to $2 \mathrm{kN} \cdot \mathrm{m}$, Acta IMEKO, vol. 6, no. 2, article 5, July 2017, identifier: IMEKO-ACTA-06 (2017)-02-05

Editor: Paul Regtien, The Netherlands

Received June 13, 2016; In final form February 1, 2017; Published July, 2017

Copyright: @ 2017 IMEKO. This is an open-access article distributed under the terms of the Creative Commons Attribution 3.0 License, which permits unrestricted use, distribution, and reproduction in any medium, provided the original author and source are credited

Corresponding author: Koji Ogushi, e-mail: kji.ogushi@aist.go.jp

\section{INTRODUCTION}

Torque standard machines (TSMs) in national metrology institutes (NMIs) have been established in many countries over the last two decades. The Korea Research Institute of Standards and Science (KRISS) has developed two deadweight-type TSMs (DWTSMs), which have rated capacities of $100 \mathrm{~N} \cdot \mathrm{m}$ and 2 $\mathrm{kN} \cdot \mathrm{m} \quad(100-\mathrm{N} \cdot \mathrm{m}-\mathrm{DWTSM}(\mathrm{K})$ and 2-kN.m-DWTSM(K), respectively) [1]. A new deadweight-type TSM with a rated capacity of $20 \mathrm{kN} \cdot \mathrm{m}(20-\mathrm{kN} \cdot \mathrm{m}-\mathrm{DWTSM}(\mathrm{K}))$ is also being developed [2]. The National Metrology Institute of Japan (NMIJ) has also developed three DWTSMs, which have rated capacities of $10 \mathrm{~N} \cdot \mathrm{m}(10-\mathrm{N} \cdot \mathrm{m}-\mathrm{DWTSM}(J))$ [3], $1 \mathrm{kN} \cdot \mathrm{m}(1-$ $\mathrm{kN} \cdot \mathrm{m}-\mathrm{DWTSM}(\mathrm{J}))$ [4], and $20 \mathrm{kN} \cdot \mathrm{m}(20-\mathrm{kN} \cdot \mathrm{m}-\mathrm{DWTSM}(\mathrm{J}))$ [5].
The first bilateral comparison between NMIJ and KRISS was performed in 2004 for the range from $200 \mathrm{~N} \cdot \mathrm{m}$ to $2 \mathrm{kN} \cdot \mathrm{m}$ by using $1-\mathrm{kN} \cdot \mathrm{m}-\mathrm{DWTSM}(\mathrm{J})$ and $20-\mathrm{kN} \cdot \mathrm{m}-\mathrm{DWTSM}(\mathrm{J})$ at NMIJ and $2-\mathrm{kN} \cdot \mathrm{m}-\mathrm{DWTSM}(\mathrm{K})$ at KRISS [6]. After that, $1-\mathrm{kN} \cdot \mathrm{m}-$ $\operatorname{DWTSM}(J)$ was improved to reduce the relative expanded uncertainty (REU) of the realized torque [7]. In order to confirm this improvement and to confirm the stability of other TSMs after the first comparison, a second bilateral comparison between NMIJ and KRISS was conducted in 2010 for the range from $50 \mathrm{~N} \cdot \mathrm{m}$ to $2 \mathrm{kN} \cdot \mathrm{m}$. Although the evaluation was put on hold after the Great East Japan Earthquake on March 11, 2011, the evaluation was resumed in 2014. This paper describes the second comparison results. We also investigated the influence 
of the voltage span of the indicator/amplifiers by using a bridge calibration unit as well as the temperature and humidity coefficients of the transducers.

\section{TORQUE STANDARD MACHINES}

\subsection{NMIJ/AIST}

Two deadweight machines, $1-\mathrm{kN} \cdot \mathrm{m}-\mathrm{DWTSM}(\mathrm{J})$ and 20 $\mathrm{kN} \cdot \mathrm{m}-\mathrm{DWTSM}(\mathrm{J})$, were used for the comparison at NMIJ. Figure 1 shows $1-\mathrm{kN} \cdot \mathrm{m}-\mathrm{DWTSM}$, which has a calibration range from $5 \mathrm{~N} \cdot \mathrm{m}$ to $1 \mathrm{kN} \cdot \mathrm{m}$. The lower limit of the range was extended to $0.5 \mathrm{~N} \cdot \mathrm{m}$ by developing a new small linkage series of weights; $1-\mathrm{kN} \cdot \mathrm{m}-\mathrm{DW} T S M(J)$ was also improved to reduce the uncertainty of the moment arm length by changing the metal band thickness at the end of the arm from $100 \mu \mathrm{m}$ to 50 $\mu \mathrm{m}$ and re-evaluating the sensitivity limit of the fulcrum (aerostatic bearing). As a result of these evaluations, REUs ( $k=$ 2) of $7.3 \times 10^{-5}$ and $2.9 \times 10^{-5}$ could be obtained for the ranges from $0.5 \mathrm{~N} \cdot \mathrm{m}$ to $20 \mathrm{~N} \cdot \mathrm{m}$ and from $5 \mathrm{~N} \cdot \mathrm{m}$ to $1 \mathrm{kN} \cdot \mathrm{m}$, respectively [7]. After some other minor changes, such as the environmental conditions, an REU of $3.4 \times 10^{-5}$ for the realized torque was obtained in the range from $5 \mathrm{~N} \cdot \mathrm{m}$ to $1 \mathrm{kN} \cdot \mathrm{m}$.

Figure 2 shows $20-\mathrm{kN} \cdot \mathrm{m}-\mathrm{DWTSM}(\mathrm{J})$, which has a calibration range from $200 \mathrm{~N} \cdot \mathrm{m}$ to $20 \mathrm{kN} \cdot \mathrm{m}$. The REU of the torque realized with the TSM was $6.7 \times 10^{-5}$ [5]. The calibration and measurement capabilities (CMCs), which equal the REUs $(k=2)$ of the calibration with almost ideal torque measuring devices (TMDs), were $3.5 \times 10^{-5}$ for $1-\mathrm{kN} \cdot \mathrm{m}-\mathrm{DWTSM}(\mathrm{J})$ from $5 \mathrm{~N} \cdot \mathrm{m}$ to $1 \mathrm{kN} \cdot \mathrm{m}$ and $7.0 \times 10^{-5}$ for $20-\mathrm{kN} \cdot \mathrm{m}-\mathrm{DWTSM}(\mathrm{J})$.

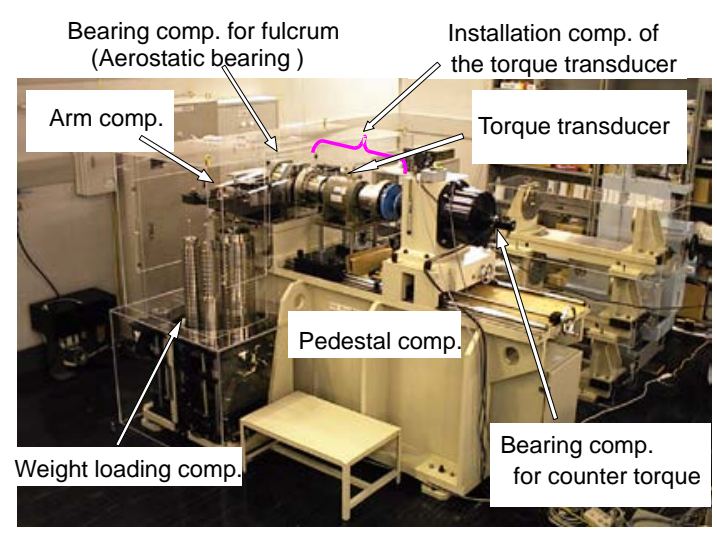

Figure 1. Components of 1-kN·m-DWTSM at NMIJ.

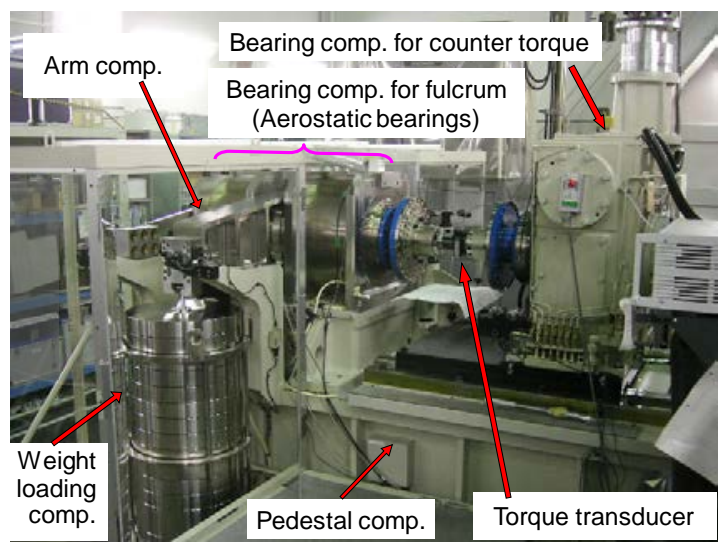

Figure 2. Components of 20-kN.m-DWTSM at NMIJ.

\subsection{KRISS}

The 2-kN·m-DWTSM $(\mathrm{K})$ deadweight machine was used for the comparison at KRISS. The CMC of $2-\mathrm{kN} \cdot \mathrm{m}-\mathrm{DWTSM}$ was evaluated as $5.0 \times 10^{-5} \quad[1]$. Figure 3 shows $2-\mathrm{kN} \cdot \mathrm{m}$ $\operatorname{DWTSM}(\mathrm{K})$. The characteristics of $2-\mathrm{kN} \cdot \mathrm{m}-\mathrm{DWTSM}$ can be found in references [1] and [6].

\section{TRANSFER DEVICES}

\subsection{Torque transducers}

Three torque transducers of different capacities were used as the transfer devices for this comparison. The three transducers, which have rated capacities of $2 \mathrm{kN} \cdot \mathrm{m}(\mathrm{TN} / 2 \mathrm{kNm}), 1 \mathrm{kN} \cdot \mathrm{m}$ $(\mathrm{TB} 2 / 1 \mathrm{kNm})$, and $100 \mathrm{~N} \cdot \mathrm{m}(\mathrm{TN} / 100 \mathrm{Nm})$, were transferred from NMIJ to KRISS by air transport. Figures 4 and 5 show

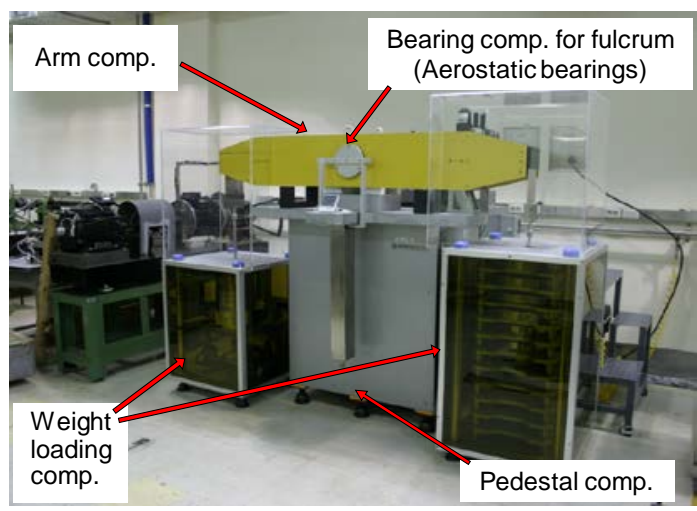

Figure 3. Components of 2-kN·m-DWTSM at KRISS.

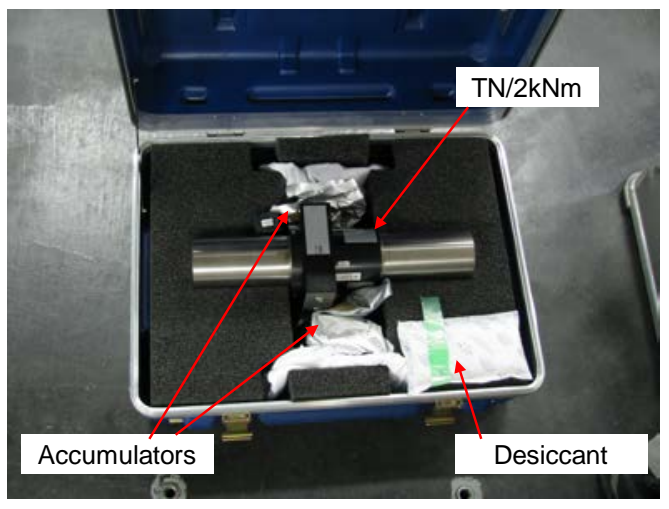

Figure 4. $2 \mathrm{kN} \cdot \mathrm{m}$ transducer and its container.

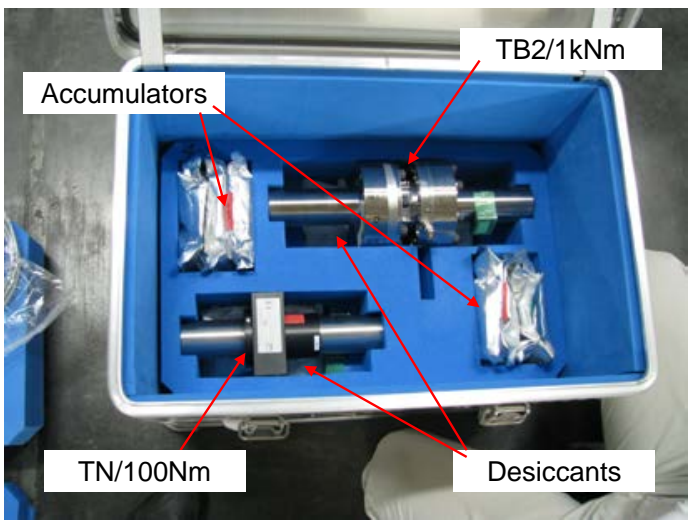

Figure $5.1 \mathrm{kN} \cdot \mathrm{m}$ and $100 \mathrm{~N} \cdot \mathrm{m}$ transducers and their container. 
the transducers and their special containers. $\mathrm{TN} / 2 \mathrm{kNm}$ and $\mathrm{TN} / 100 \mathrm{Nm}$ are shaft-type transducers, whereas $\mathrm{TB} 2 / 1 \mathrm{kNm}$ is a disk-type transducer. The adapter flanges were kept fastened to both sides of TB2 $/ 1 \mathrm{kNm}$ for more than one year before the comparison. The $100 \mathrm{~N} \cdot \mathrm{m}$ transducer of $\mathrm{TN} / 100 \mathrm{Nm}$ has double bridges so that two series of outputs were available. The output from bridge 1 is expressed as TN/100Nm(MD1), whereas that of bridge 2 is expressed as TN/100Nm(MD2). The containers sealed the transducers from the outside environment. Accumulators $\left(20{ }^{\circ} \mathrm{C}\right.$ to $\left.25{ }^{\circ} \mathrm{C}\right)$ and desiccants ( $40 \%$ relative humidity) were put into the containers to maintain the lab environment as much as possible. Thermohygrometers and a 3-D accelerometer were placed in the container to monitor the environmental conditions. The sampling period of the thermo-hygrometers was 30 minutes. The variations in temperature and relative humidity during transportation were from $10{ }^{\circ} \mathrm{C}$ to $24{ }^{\circ} \mathrm{C}$ and from $28 \%$ to $63 \%$, respectively. The sampling period of the accelerometer was $0.5 \mathrm{~s}$, and the maximum acceleration was recorded for every hour. The containers inadvertently received a maximum shock of $76 \mathrm{~m} / \mathrm{s}^{2}$ (one time) during transportation. However, no serious damage was found in the transducer after unpacking.

Figures 6(a)-6(d) indicate the long-term stabilities of $\mathrm{TN} / 2 \mathrm{kNm}$, TB2 $/ 1 \mathrm{kNm}$, and $\mathrm{TN} / 100 \mathrm{Nm}(\mathrm{MD} 1$ and $\mathrm{MD} 2)$ before the comparison. The long-term stability was expressed by relative deviations of the calibration results at the rated capacities from the mean values of all calibration results during a certain period. $\mathrm{TN} / 2 \mathrm{kNm}$ and both bridges of $\mathrm{TN} / 100 \mathrm{Nm}$ were stable, and the maximum variation over approximately three months was less than $1.0 \times 10^{-5}$. The variation of

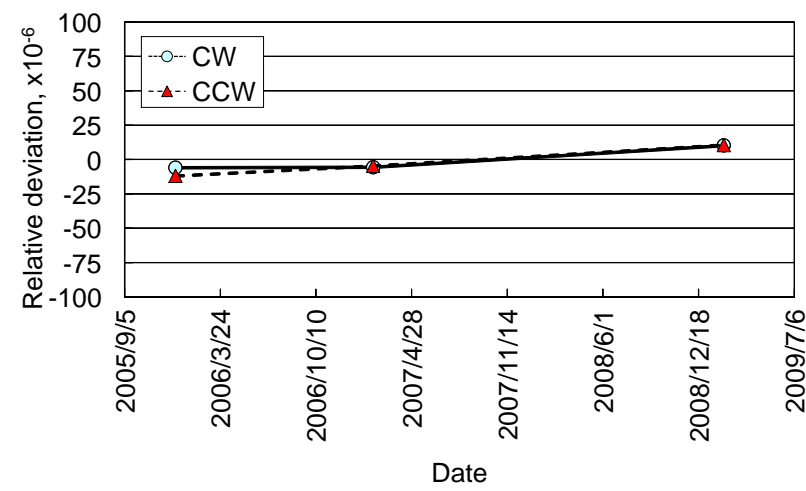

(a) $\mathrm{TN} / 2 \mathrm{kNm}$

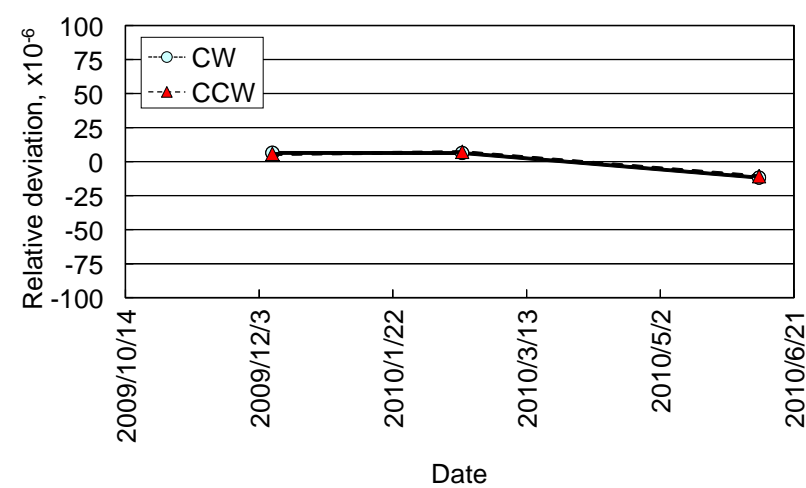

(c) TN/100Nm(MD1)
TB2 $/ 1 \mathrm{kNm}$ over approximately one and half years was $7.0 \times$ $10^{-5}$. Although the variation was relatively large, the tendency of the variation was approximately linear, and the change in calibration results within three months was less than $2.0 \times 10^{-5}$, so the authors decided that the transducer could be used as a transfer standard.

The temperature and humidity coefficients of all transducers were investigated after the comparison in order to correct the results depending on the environmental conditions during each measurement. The detailed procedure and results are explained and discussed in Sections 4.2 and 5.3.

\subsection{Amplifier/indicators and bridge calibration unit}

The bridge calibration unit $\mathrm{BN} 100 \mathrm{~A}(\mathrm{~J})$, which calibrates the AC bridge voltage with an excitation voltage of $5 \mathrm{~V}$ and a carrier frequency of $225 \mathrm{~Hz}$, was also transferred from NMIJ to KRISS by air transport. The amplifier/indicator of each NMI (DMP40S2 $\left(J_{a}\right)$ and DMP40S2 $\left(J_{b}\right)$ at NMIJ and DMP40(K) at KRISS) was connected to the transfer transducers during each torque calibration. At NMIJ, DMP40S2 (Ja) was used for the calibrations of $\mathrm{TB} 2 / 1 \mathrm{kNm}$ and $\mathrm{TN} / 100 \mathrm{Nm}$, whereas DMP40S2 $\left(J_{b}\right)$ was used for the calibrations of $T N / 2 \mathrm{kNm}$. At KRISS, DMP40(K) was used for the calibrations of all transducers. The amplifier/indicators were calibrated just before and immediately after each torque calibration by $\mathrm{BN100A}(J)$. Figure 7 shows BN100A(J) and DMP40(K). The reference voltage ratios of the bridge calibration unit were measured by the amplifier/indicators at steps of $+0,+0.1,+0.5$, $+0.7,+0.8,+1.0,+1.4$, and $+1.6 \mathrm{mV} / \mathrm{V}$ and then $-0,-0.1,-0.5$, $-0.7,-0.8,-1.0,-1.4$, and $-1.6 \mathrm{mV} / \mathrm{V}$. Bridge voltage calibration was carried out 10 times during this comparison calibration, as

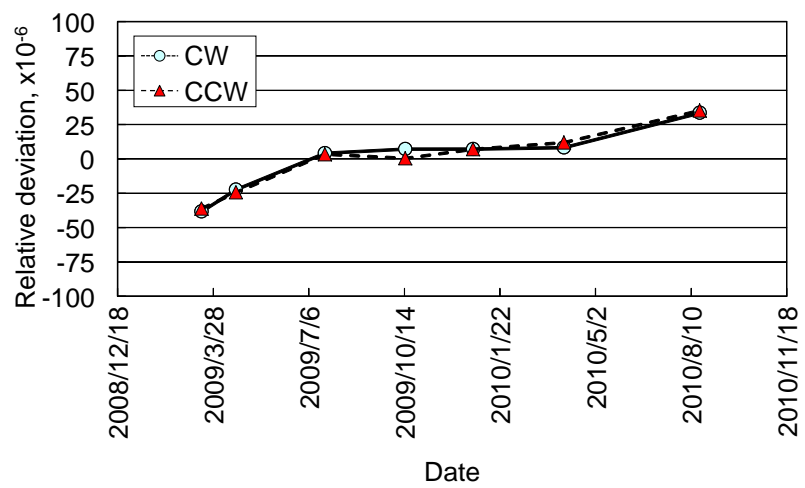

(b) TB2/1kNm

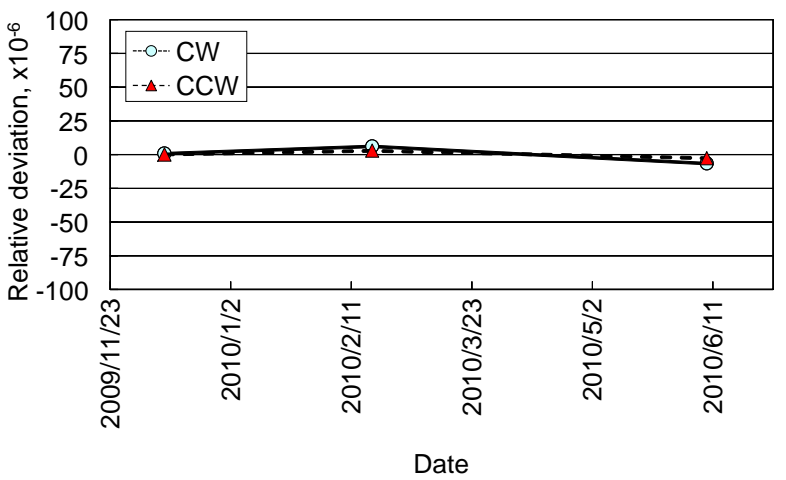

(d) $\mathrm{TN} / 100 \mathrm{Nm}(\mathrm{MD2})$

Figure 6. Long-term stabilities of the torque transducers. 


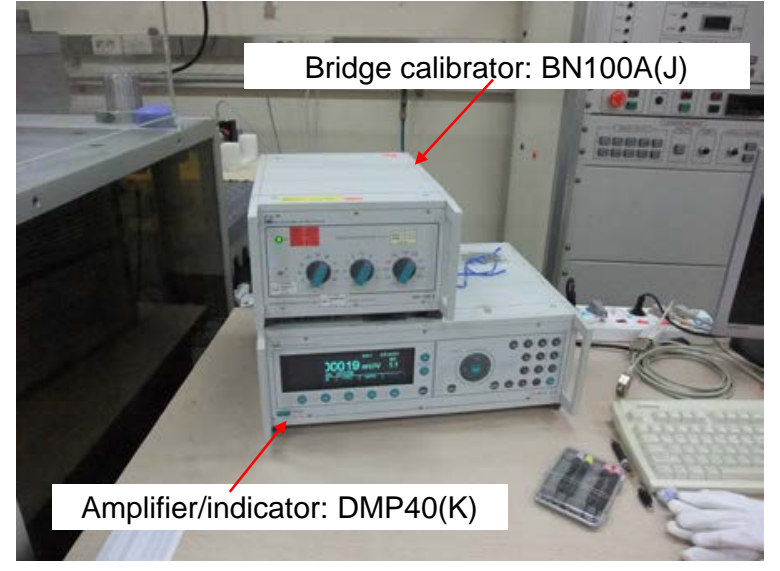

Figure 7. Bridge calibration unit and amplifier/indicator.

follows:

(V1) DMP40S2 (Ja) calibrated by BN100A(J) before pre-cal. at NMIJ

(V2) DMP40S2 $\left(J_{a}\right)$ calibrated by BN100A(J) after pre-cal. at NMIJ

(V3) DMP40S2 (J $\mathrm{b}_{\mathrm{b}}$ calibrated by BN100A(J) before pre-cal. at NMIJ

(V4) DMP40S2(Jb) calibrated by BN100A(J) after pre-cal. at NMIJ

(V5) DMP40(K) calibrated by BN100A(J) before calibration at KRISS

(V6) DMP40(K) calibrated by BN100A(J) after calibration at KRISS

(V7) DMP40S2 $\left(\mathrm{J}_{\mathrm{a}}\right)$ calibrated by BN100A (J) before post-cal. at NMIJ

(V8) DMP40S2 $\left(J_{a}\right)$ calibrated by BN100A(J) after post-cal. at NMIJ

(V9) DMP40S2(J b) calibrated by BN100A(J) before post-cal. at NMIJ

(V10) DMP40S2(J $)_{b}$ calibrated by BN100A(J) after post-cal. at NMIJ

The above procedure was able to evaluate the stability and differences of amplifier/indicators during the entire comparison calibration. Results are discussed in Section 5.1.

\section{EXPERIMENTAL PROCEDURE}

\subsection{Comparison calibration procedure}

Pre- and post-calibrations were conducted at NMIJ (we call the pre-calibration "J1" and the post-calibration "J2") by three transducers (four bridges) before and after the calibration at KRISS (we call the calibration " $K$ "). Loading timetables for the individual calibrations are shown in Figure 8. The timetable used in the CIPM key comparison of CCM.T-K2 [8] was adopted. The torque calibration was conducted separately in both the clockwise (CW) and counterclockwise (CCW)

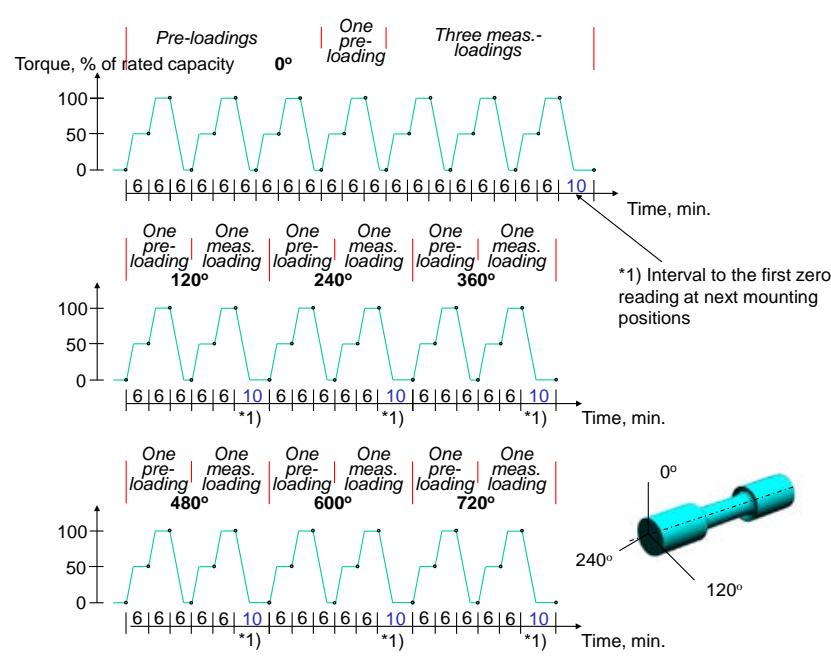

Figure 8. Loading timetable of calibration for each torque transducer. directions. Table 1 shows the overall schedule of the comparison.

The rotational mounting position of each transducer was changed to three pitch directions (every $120^{\circ}$ ) and rotated twice. First, after three pre-loading cycles up to the maximum torque (the rated capacity of the torque transducer) in two steps of $50 \%$ and $100 \%$ of the maximum torque, the combination of one pre-loading and three measurement loading cycles was conducted at the $0^{\circ}$ direction. In all cycles, the torque steps were increasing only. The combination of one pre-loading and one measurement loading cycle was performed in the directions of $120^{\circ}, 240^{\circ}, 360^{\circ}, 480^{\circ}, 600^{\circ}$, and $720^{\circ}$. The time intervals were strictly maintained to exclude the influence of the creep characteristics of transducers. The interval from the start of loading to data acquisition was six minutes. The interval from the last maximum torque reading at the present mounting position to the first zero reading at the next mounting position was ten minutes.

\subsection{Determination procedure of temperature and humidity coefficients}

The principle of measurement for the torque transducers used in this comparison was the strain gauge. The output of this type of transducer generally depends on the environmental temperature and humidity [9]. After the comparison calibration, therefore, temperature and humidity coefficients were experimentally determined. We prepared the following five conditions in the torque calibration rooms at $\mathrm{NMIJ}$, and torque was loaded on the transducers in steps of $50 \%$ and $100 \%$ of the maximum torque, as was done in the comparison calibration procedure (but with only three pre-loading cycles and one measurement loading cycle at only the $0^{\circ}$ position, and the time interval was approximately 40 seconds, but not six minutes).

DATA $1: 23{ }^{\circ} \mathrm{C}, 40 \%$

DATA 2: $25^{\circ} \mathrm{C}, 40 \%$

DATA 3: $27^{\circ} \mathrm{C}, 40 \%$

DATA $4: 27^{\circ} \mathrm{C}, 50 \%$

DATA 5: $27^{\circ} \mathrm{C}, 60 \%$

From the measurement values of the five conditions, temperature coefficient $\alpha_{\mathrm{t}}$ and humidity coefficient $\beta_{\mathrm{h}}$ were estimated for both the $50 \%$ and $100 \%$ steps and for both the $\mathrm{CW}$ and $\mathrm{CCW}$ directions of all bridges.

\section{RESULTS AND DISCUSSION}

\subsection{Stability and differences of amplifier/indicators}

All measurement results are summarized in Figures 9(a) and 9(b), where the relative deviation of each step from the start of measurement is expressed. Figures 9(a) and 9(b) are the cases referring to DMP40S2 $\left(J_{a}\right)$ and DMP40S2 $\left(J_{b}\right)$, respectively. In both cases, very small voltage span variations occurred except at the steps of $\pm 0.1 \mathrm{mV} / \mathrm{V}$. From the differences of voltage

Table 1. Schedule of measurements and transportation.

\begin{tabular}{c|c}
\hline $\begin{array}{c}\text { Pre-calibration at } \\
\text { NMIJ (J1) }\end{array}$ & September 13 - September 24, 2010 \\
\hline Transportation & September 24-October 5, 2010 \\
\hline $\begin{array}{c}\text { Calibration at KRISS } \\
(\mathrm{K})\end{array}$ & October 5-October 21, 2010 \\
\hline Transportation & October 26 - October 29, 2010 \\
\hline $\begin{array}{c}\text { Post-calibration at } \\
\text { NMIJ (J2) }\end{array}$ & November 1 - December 2, 2010 \\
\hline
\end{tabular}




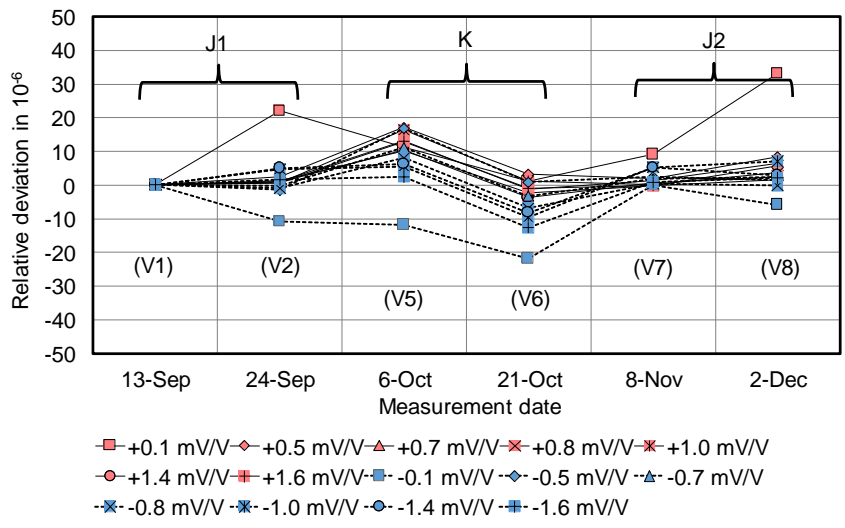

(a) Referring to DMP40S2 $\left(J_{a}\right)$

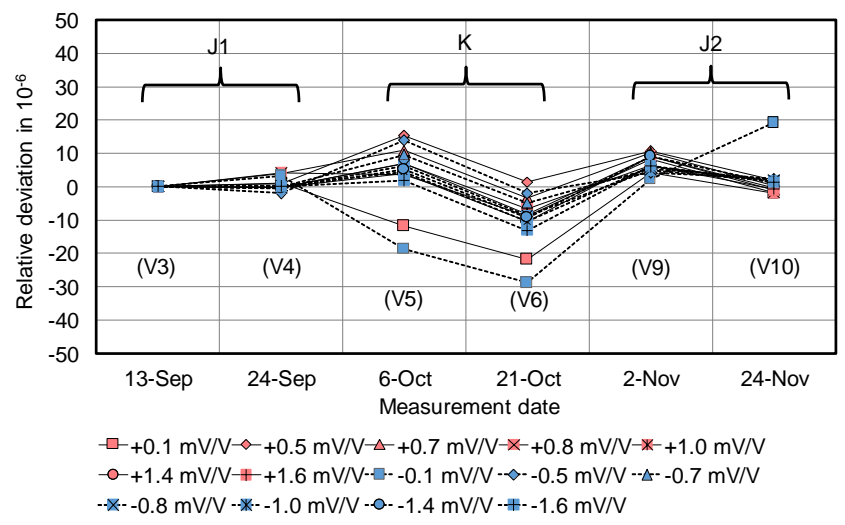

(b) Referring to DMP40S2 $\left(\mathrm{J}_{\mathrm{b}}\right)$

Figure 9. Stability and differences of voltage span in amplifier/indicators.

ratios between DMP40s in NMIJ and KRISS, we calculated correction factors and uncertainties for the torque calibration values obtained in KRISS according to the procedure in reference [6], as shown in Table 2. The correction factors are so small that they would not affect the final results of the comparison. Nevertheless, these factors were used for the correction of the results in Sections 5.3 and 5.4.

\subsection{Calibration results of torque without correction}

The calibration results were calculated by using the following equation for the mean of the measured values which are defined as each indicated value minus the zero value at the prior loading cycle, at the measurement loading cycles for all mounting positions except the $0^{\circ}$ direction:

$\overline{S_{i}^{\prime}}=\frac{1}{n_{\text {rot }}} \sum_{\mathrm{e}=1}^{n_{\text {rot }}} S_{\text {i1e }}^{\prime}$

where $S_{\text {ije }}$ is the measured value in the measurement loading cycle for step i, cycle $\mathrm{j}(=1)$, and series e (where "series" means the successive calibration sequence within the same mounting position), and $n_{\text {rot }}$ is the number of rotational mounting positions $\left(n_{\mathrm{rot}}=6\right)$. The relative deviations of the calibration results obtained at KRISS from the mean results of the pre- and post-calibrations at NMIJ are shown in Figures $10(\mathrm{a})-10(\mathrm{~d})$ (with white squares) for $\mathrm{TN} / 2 \mathrm{kNm}$, TB2 $/ 1 \mathrm{kNm}$, $\mathrm{TN} / 100 \mathrm{Nm}(\mathrm{MD} 1)$, and $\mathrm{TN} / 100 \mathrm{Nm}(\mathrm{MD} 2)$, respectively. The short-term drift, which is expressed by (11) in Section 5.4.5, is defined as the difference in the results between the pre- and post-calibrations at NMIJ. The relative values of the short-term drift are also shown in Figure 10 (with white circles).

At the calibration points for $2 \mathrm{kN} \cdot \mathrm{m}, 1 \mathrm{kN} \cdot \mathrm{m}, 500 \mathrm{~N} \cdot \mathrm{m}, 100$ $\mathrm{N} \cdot \mathrm{m}$, and $50 \mathrm{~N} \cdot \mathrm{m}$, the relative deviations were from $0.2 \times 10^{-5}$ to $5.0 \times 10^{-5}$. At some points, very small deviations were obtained, whereas relatively large deviations occurred in the 50 $\mathrm{N} \cdot \mathrm{m}$ and $100 \mathrm{~N} \cdot \mathrm{m}$ steps. The deviation tendency in $\mathrm{TN} / 100 \mathrm{Nm}(\mathrm{MD} 1)$ was similar to that in $\mathrm{TN} / 100 \mathrm{Nm}(\mathrm{MD} 2)$. The deviation of $\mathrm{TN} / 2 \mathrm{kNm}$ in the $\mathrm{CW}$ direction became larger than the others. The authors presume that the differences in such deviation levels are due to the differences in environmental conditions, humidity in particular. The environmental conditions during each torque calibration are summarized in Table 3. Some of the short-term drifts of the transducers for approximately two months were also larger than the others $\left(0.3 \times 10^{-5}\right.$ to $\left.3.8 \times 10^{-5}\right)$.

\subsection{Determination of temperature and humidity coefficients}

Figure 11 shows the actual temperature and relative humidity measured at each condition and for each transducer (as described in Section 4.2). Because the torque calibration rooms are very huge, the temperature and humidity are very stable, but it was difficult to precisely set the temperature and humidity to objective values. The dispersions and deviations occurred even

Table 2. Correction factors due to differences of voltage ratios.

\begin{tabular}{|c|c|c|c|c|}
\hline Transducer & Torque steps in $\mathrm{N} \cdot \mathrm{m}$ & $\begin{array}{c}\text { Equivalent voltage ratio } \\
\text { steps in } \mathrm{mV} / \mathrm{V}\end{array}$ & $\begin{array}{l}\text { Correction factor for } \\
\text { KRISS values }\end{array}$ & $\begin{array}{c}\text { Relative standard } \\
\text { uncertainty }\end{array}$ \\
\hline $\mathrm{TN} / 2 \mathrm{kNm}$ & $\begin{array}{c}1000 \\
2000 \\
-1000 \\
-2000 \\
\end{array}$ & $\begin{array}{c}+0.7 \text { to }+0.8 \\
+1.4 \text { to }+1.6 \\
-0.7 \text { to }-0.8 \\
-1.4 \text { to }-1.6\end{array}$ & $\begin{array}{l}1.000003 \\
1.000003 \\
1.000000 \\
1.000005\end{array}$ & $\begin{array}{l}\text { 1.2.E-05 } \\
\text { 1.2.E-05 } \\
\text { 1.1.E-05 } \\
\text { 1.1.E-05 }\end{array}$ \\
\hline $\mathrm{TB} 2 / 1 \mathrm{kNm}$ & $\begin{array}{c}500 \\
1000 \\
-500 \\
-1000\end{array}$ & $\begin{array}{c}+0.5 \\
+1.0 \\
-0.5 \\
-1.0\end{array}$ & $\begin{array}{l}0.999993 \\
0.999992 \\
0.999992 \\
1.000006\end{array}$ & $\begin{array}{l}\text { 1.1.E-05 } \\
\text { 1.1.E-05 } \\
\text { 1.2.E-05 } \\
\text { 1.1.E-05 }\end{array}$ \\
\hline $\mathrm{TN} / 100 \mathrm{Nm}(\mathrm{MD} 1)$ & $\begin{array}{c}50 \\
100 \\
-50 \\
-100\end{array}$ & $\begin{array}{c}+0.7 \text { to }+0.8 \\
+1.4 \text { to }+1.6 \\
-0.7 \text { to }-0.8 \\
-1.4 \text { to }-1.6\end{array}$ & $\begin{array}{l}0.999997 \\
0.999996 \\
0.999998 \\
1.000005\end{array}$ & $\begin{array}{l}\text { 1.1.E-05 } \\
\text { 1.1.E-05 } \\
\text { 1.0.E-05 } \\
\text { 1.0.E-05 }\end{array}$ \\
\hline $\mathrm{TN} / 100 \mathrm{Nm}(\mathrm{MD} 2)$ & $\begin{array}{c}50 \\
100 \\
-50 \\
-100\end{array}$ & $\begin{array}{c}+0.7 \text { to }+0.8 \\
+1.4 \text { to }+1.6 \\
-0.7 \text { to }-0.8 \\
-1.4 \text { to }-1.6\end{array}$ & $\begin{array}{l}0.999997 \\
0.999996 \\
0.999998 \\
1.000005\end{array}$ & $\begin{array}{l}\text { 1.1.E-05 } \\
\text { 1.1.E-05 } \\
\text { 1.0.E-05 } \\
\text { 1.0.E-05 }\end{array}$ \\
\hline
\end{tabular}




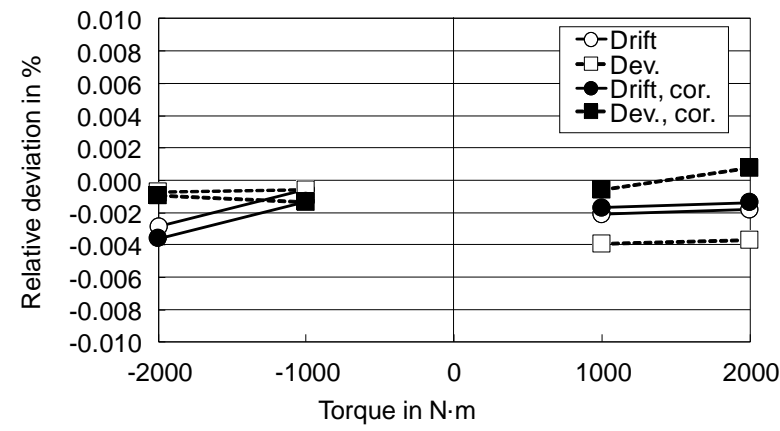

(a) $\mathrm{TN} / 2 \mathrm{kNm}$

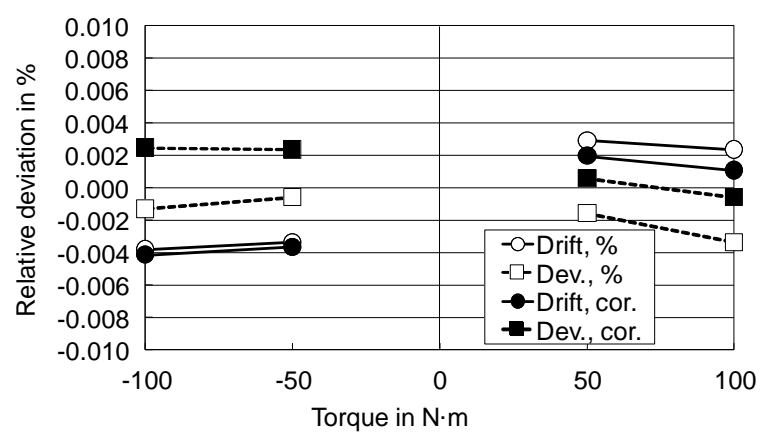

(c) $\mathrm{TN} / 100 \mathrm{Nm}(\mathrm{MD} 1)$

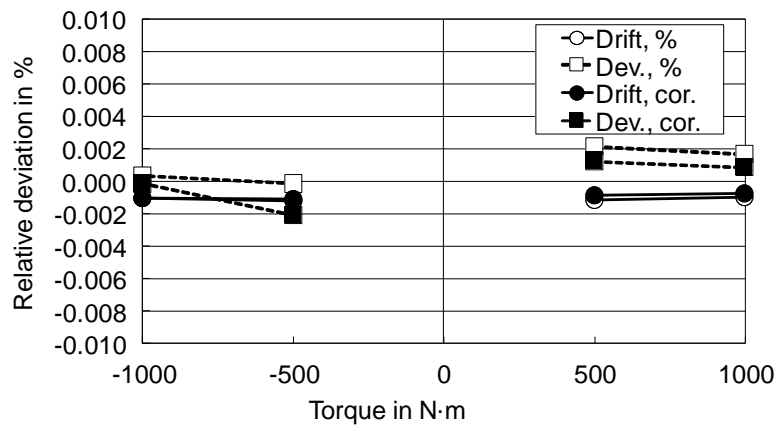

(b) TB2/1kNm

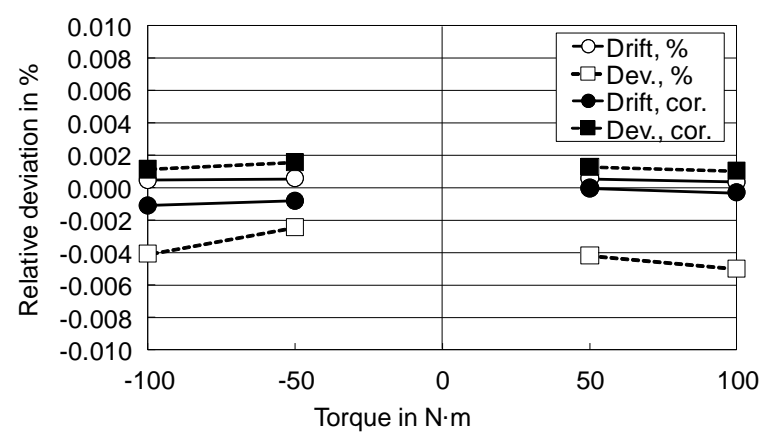

(d) TN/100Nm(MD2)

Figure 10. Relative deviation and short-term drift of calibration results.

Table 3. Temperature and humidity conditions at each measurement.

\begin{tabular}{c|c:c|c:c|c:c}
\hline & $\mathrm{J} 1$ & $\mathrm{~J} 1$ & $\mathrm{~K}$ & $\mathrm{~K}$ & $\mathrm{~J} 2$ & $\mathrm{~J} 2$ \\
& Temp. in ${ }^{\circ} \mathrm{C}$ & R. H. in $\%$ & Temp. in ${ }^{\circ} \mathrm{C}$ & R. H. in $\%$ & Temp. in ${ }^{\circ} \mathrm{C}$ & R. H. in $\%$ \\
\hline
\end{tabular}

\begin{tabular}{|c|c|c|c|c|c|c|c|}
\hline \multicolumn{8}{|c|}{$\mathrm{TN} / 2 \mathrm{kNm}$} \\
\hline $\mathrm{CW}$ & Min. & 22.9 & 36 & $23.1:$ & 49 & $22.8 !$ & 37 \\
\hline \multirow{3}{*}{$\mathrm{CCW}$} & Max. & 23.1 & 37 & 23.5 & 53 & 22.9 & 39 \\
\hline & Min. & 22.7 & 37 & 23.3 & 36 & 22.9 & 37 \\
\hline & Max. & 22.9 & 45 & 23.5 & 42 & 23.0 & 39 \\
\hline \multicolumn{8}{|c|}{$\mathrm{TB} 2 / 1 \mathrm{kNm}$} \\
\hline \multirow[t]{2}{*}{$\mathrm{CW}$} & Min. & 23.1 & 41 & 23.3 & 47 & 22.7 & 39 \\
\hline & Max. & 23.3 & 42 & 23.6 & 50 & 23.0 & 40 \\
\hline \multirow[t]{2}{*}{$\mathrm{CCW}$} & Min. & 23.2 & 40 & 23.4 & 48 & 22.8 & 40 \\
\hline & Max. & 23.3 & 40 & 23.6 & 51 & 23.0 & 44 \\
\hline \multicolumn{8}{|c|}{$\mathrm{TN} / 100 \mathrm{Nm}(\mathrm{MD} 1)$} \\
\hline \multirow[t]{2}{*}{$\mathrm{CW}$} & Min. & 23.1 & 40 & 22.6 & 50 & $22.8 \vdots$ & 39 \\
\hline & Max. & 23.2 & 47 & 22.9 & 53 & 22.9 & 40 \\
\hline \multirow[t]{2}{*}{$\mathrm{CCW}$} & Min. & 23.0 & 42 & 23.0 & 52 & 22.8 & 40 \\
\hline & Max. & 22.9 & 39 & 22.9 & 51 & 22.7 & 40 \\
\hline \multicolumn{8}{|c|}{$\mathrm{TN} / 100 \mathrm{Nm}(\mathrm{MD} 2)$} \\
\hline \multirow[t]{2}{*}{$\mathrm{CW}$} & Min. & $23.1 \vdots$ & 40 & 22.6 & 50 & 22.8 & 39 \\
\hline & Max. & 23.2 & 47 & 22.9 & 53 & 22.9 & 40 \\
\hline \multirow[t]{2}{*}{$\mathrm{CCW}$} & Min. & 23.0 & 42 & 23.0 & 52 & 22.8 & 40 \\
\hline & Max. & 23.0 & 42 & 23.0 & 52 & 22.8 & 40 \\
\hline
\end{tabular}

under the same conditions.

Nevertheless, DATA 3, 4, and 5 have comparably similar temperature values (around $27.3{ }^{\circ} \mathrm{C}$ ). So, we decided to carry out the following procedures:

(1) Humidity coefficient $\beta_{\mathrm{h}}$ for each transducer, each direction and each step was estimated by fitting the linear curve for three measurement results of DATA 3, 4, and 5 .

(2) Measurement values of DATA 1 and 2 were corrected to values at the humidity of DATA 3 by using the humidity coefficient obtained by procedure (1).

(3) Corrected measurement values of DATA 1, 2, and 3 have the same humidity conditions and different temperature 


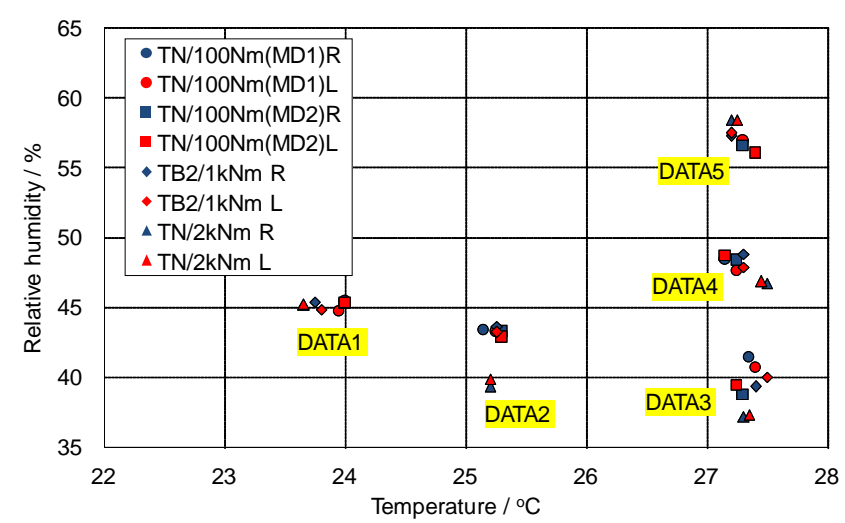

Figure 11. Actual temperature and relative humidity at each experimental condition to determine the temperature and humidity coefficients of the torque transducers.

conditions. Then, temperature coefficient $\alpha_{\mathrm{t}}$ for each transducer, each direction and each step was estimated by fitting the linear curve for three corrected measurement results of DATA 1,2 , and 3 .

For example, the estimated $\alpha_{\mathrm{t}}$ and $\beta_{\mathrm{h}}$ were obtained from the gradient of slopes shown in Figure 12, for all steps and all directions in the case of $\mathrm{TN} / 2 \mathrm{kNm}$. Here, the blue values (circles) correspond to the left ordinate axis and the red ones (diamonds) to the right one. The coefficients for other transducers were also successfully obtained. All values of $\alpha_{\mathrm{t}}$ and $\beta_{\mathrm{h}}$, and their standard uncertainties (standard deviations of the fitting curves) are summarized in Table 4.

All of the comparison calibration results in Figure 10 were corrected by the following equations:

$\left.\overline{S_{\mathrm{i}}^{\prime}}\right|_{\mathrm{h} 40}=\overline{S_{\mathrm{i}}^{\prime}}-\beta_{\mathrm{h}}(b-40 \%)$ and

$\left.\overline{S_{i}^{\prime}}\right|_{\mathrm{t} 23}=\overline{S_{i}^{\prime}}-\alpha_{\mathrm{t}}\left(t-23^{\circ} \mathrm{C}\right)$,

where $b$ and $t$ are the mean values of the relative humidity and the temperature, respectively, which were measured during torque calibration for obtaining the result $\overline{S_{i}^{\prime}}$, and $\left.\overline{S^{\prime}}\right|_{\mathrm{h} 40}$ and $\left.\overline{S^{\prime}}{ }_{\mathrm{i}}\right|_{\mathrm{t} 23}$ are corrected values at relative humidity $b=40 \%$ and temperature $t=23{ }^{\circ} \mathrm{C}$ (reference humidity and reference

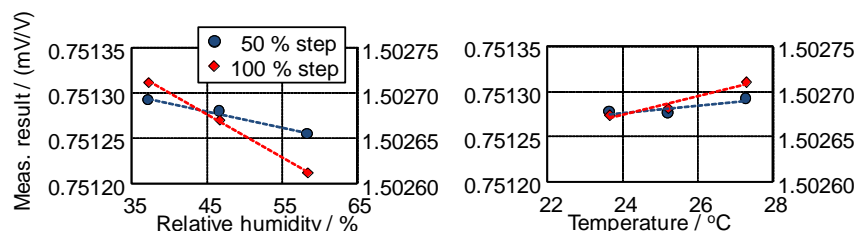

(a) $\beta_{\mathrm{h}}$ for $\mathrm{CW}$ direction

(b) $\alpha_{\mathrm{t}}$ for $\mathrm{CW}$ direction

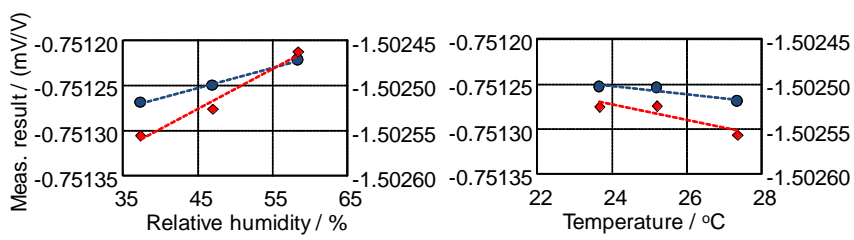

(c) $\beta_{\mathrm{h}}$ for CCW direction

(d) $\alpha_{\mathrm{t}}$ for $\mathrm{CCW}$ direction

Figure 12. Estimated temperature and humidity coefficients (TN/2kNm)). temperature, respectively). In addition, calibration results were corrected by referring the influence of the voltage ratio differences by multiplying correction factors in Table 2 .

The calculation results of the short-term drift (with black circles) and the relative deviation (with black squares) between NMIJ and KRISS obtained by using the above corrected values are shown in Figure 10. Almost all relative deviations became smaller than the values without correction. In particular, correction of the humidity achieved good results. On the other hand, short-term drifts did not change much because temperature and humidity conditions were not very different between pre- and post-calibrations at NMIJ.

\subsection{Evaluation of $E_{\mathrm{n}}$ numbers}

The uncertainties of calibrations including corrections were calculated according to the following equations and procedure. Then, we could finally compare the results of the two NMIs by using the $E_{\mathrm{n}}$ numbers.

\subsubsection{Reproducibility with changing mounting position}

The relative reproducibility with changing mounting position $b$ was estimated by defining an experimental standard deviation in the measured values for the first measurement loading cycles in all directions, $120^{\circ}, 240^{\circ}, 360^{\circ}, 480^{\circ}, 600^{\circ}$, and $720^{\circ}$, as follows:

$$
b_{\mathrm{i}}=\frac{1}{\left|\overline{S^{\prime}}\right|} \sqrt{\frac{1}{n_{\mathrm{rot}}-1} \sum_{\mathrm{e}=1}^{n_{\mathrm{rot}}}\left(S_{\mathrm{i} 1 \mathrm{e}}^{\prime}-\overline{S^{\prime}}\right)^{2}} .
$$

The relative standard uncertainty $w_{\text {rot }}$ is calculated as "an experimental standard deviation of the mean" by the following equation:

$$
w_{\text {rot, } \mathrm{i}}^{2}=\frac{1}{n_{\text {rot }}} b_{\mathrm{i}}^{2} .
$$

\subsubsection{Repeatability with unchanged mounting position}

The relative repeatability with the unchanged mounting position $b$ ' was estimated by defining the experimental standard deviation of the measured values for three measurement loading cycles in the $0^{\circ}$ direction as follows:

$b_{\mathrm{i}}{ }^{\prime}=\frac{1}{\sqrt{S_{\mathrm{i}, \text { rep }}^{\prime}} \mid} \sqrt{\frac{1}{n_{\text {rep }}-1} \sum_{\mathrm{j}=1}^{n_{\text {rep }}}\left(S_{\mathrm{i} j 0}^{\prime}-\overline{S_{\mathrm{i}, \text { rep }}^{\prime}}\right)^{2}}$,

where $\overline{S_{i, \text { rep }}^{\prime}}$ is the mean value of the three measured values in the $0^{\circ}$ direction $\left(\mathrm{e}=0, n_{\mathrm{rep}}=3\right)$.

The relative standard uncertainty $w_{\text {rep }}$ is also calculated as "an experimental standard deviation of the mean" by the following equation:

$$
w_{\text {rep,i }}^{2}=\frac{1}{n_{\text {rep }}} b_{i}{ }^{2} \text {. }
$$

\subsubsection{Zero point shift}

The relative zero point shift $f_{0}$ was estimated by defining the deviation between the zero signals prior to the increasing torque and after the decreasing torque in the first and second cycles of the $0^{\circ}$ direction, as follows:

$f_{0, j 0}=\frac{S_{0 j 0}^{\prime \prime}-S_{0 j 0}^{\prime}}{\left|S_{n j 0}^{\prime}\right|}$ 
Table 4. Temperature and humidity coefficients for torque transducers and their uncertainties.

\begin{tabular}{|c|c|c|c|c|c|}
\hline Transducer & $\begin{array}{c}\text { Torque steps } \\
\mathrm{N} \cdot \mathrm{m}\end{array}$ & $\begin{array}{c}\text { Temperature } \\
\text { coefficient } \\
(\mathrm{mV} / \mathrm{V}) / \mathrm{K}\end{array}$ & $\begin{array}{c}\text { Standard } \\
\text { uncertainty } \\
(\mathrm{mV} / \mathrm{V}) / \mathrm{K} \\
\end{array}$ & $\begin{array}{l}\text { Humidity } \\
\text { coefficient } \\
(\mathrm{mV} / \mathrm{V}) / \%\end{array}$ & $\begin{array}{c}\text { Standard } \\
\text { uncertainty } \\
(\mathrm{mV} / \mathrm{V}) / \%\end{array}$ \\
\hline \multirow{4}{*}{$\mathrm{TN} / 2 \mathrm{kNm}$} & 1000 & 4.0.E-06 & 2.5.E-06 & -1.8.E-06 & 2.7.E-07 \\
\hline & 2000 & 1.0.E-05 & 2.6.E-06 & -4.7.E-06 & 2.2.E-07 \\
\hline & -1000 & -4.6.E-06 & 1.8.E-06 & 2.2.E-06 & 1.3.E-07 \\
\hline & -2000 & -8.7.E-06 & 4.4.E-06 & 4.4.E-06 & 6.7.E-07 \\
\hline \multirow{4}{*}{$\mathrm{TB} 2 / 1 \mathrm{kNm}$} & 500 & 4.8.E-06 & 1.8.E-06 & -1.2.E-07 & 5.2.E-07 \\
\hline & 1000 & 1.0.E-05 & 4.1.E-06 & -4.3.E-07 & 1.1.E-06 \\
\hline & -500 & -3.2.E-06 & 5.3.E-07 & -5.1.E-07 & 1.3.E-07 \\
\hline & -1000 & -6.0.E-06 & 1.8.E-06 & -1.1.E-06 & 1.3.E-07 \\
\hline \multirow{4}{*}{ TN/100Nm(MD1) } & 50 & 3.3.E-06 & 3.1.E-06 & -2.0.E-06 & 1.3.E-07 \\
\hline & 100 & 8.0.E-06 & 2.5.E-06 & -5.2.E-06 & 3.4.E-07 \\
\hline & -50 & -4.1.E-06 & 2.9.E-08 & 2.2.E-06 & 1.3.E-07 \\
\hline & -100 & -7.3.E-06 & 2.0.E-06 & 4.5.E-06 & 3.7.E-07 \\
\hline \multirow{4}{*}{$\mathrm{TN} / 100 \mathrm{Nm}(\mathrm{MD} 2)$} & 50 & -9.0.E-07 & 3.8.E-07 & -3.1.E-06 & 3.2.E-07 \\
\hline & 100 & -2.9.E-06 & 2.0.E-06 & -6.8.E-06 & 5.2.E-07 \\
\hline & -50 & 3.0.E-06 & 3.1.E-07 & 2.8.E-06 & 9.2.E-07 \\
\hline & -100 & 4.8.E-06 & 3.6.E-07 & 6.3.E-06 & 1.3.E-06 \\
\hline
\end{tabular}

where $\mathrm{i}=\mathrm{n}$ is the maximum torque step. The zero point shift cannot be calculated in the last measurement loading cycles because the zero signals after the decreasing torque were read after changing the mounting positions (see Figure 8). The relative standard uncertainty $w_{\text {zer }}$ was calculated according to the following equation, considering the mean deviation $f_{0, \text { mean }}$ in two $f_{0, j 0}$ as the half-width of the rectangular distribution:

$w_{\text {zer }}^{2}=\frac{1}{3} f_{0, \text { mean }}^{2}$.

\subsubsection{Resolution}

In the case of a digital scale, resolution $r$ is defined as one increment in the last active number of the amplifier/indicator when the indication does not fluctuate under the no-load condition. If the indication fluctuates, then $r$ is determined to be half the range of the fluctuation. Here, $r$ is stated in units of torque $(\mathrm{N} \cdot \mathrm{m})$.

The uncertainty due to the resolution should be taken into account twice, because each measured value is obtained as the difference between the step-indicated value and the zeroindicated value. The relative standard uncertainty $w_{\text {res }}$ was calculated by the following equations for the applied torque $T_{\mathrm{i}}$ $(\mathrm{N} \cdot \mathrm{m})$ at step i:

1) Considering the resolution $r$ as the whole width of the rectangular distribution when the indication does not fluctuate under the no-load condition:

$w_{\text {res,i }}^{2}=\frac{2}{3}\left(\frac{r}{2 T_{\mathrm{i}}}\right)^{2}$.

2) Considering the resolution $r$ as the half-width of the rectangular distribution when the indication fluctuates:

$w_{\mathrm{res}, \mathrm{i}}^{2}=\frac{2}{3}\left(\frac{r}{T_{\mathrm{i}}}\right)^{2}$

The low-pass frequency of the amplifier/indicators was always set to " $0.1 \mathrm{~Hz}$ Bessel" during this bilateral comparison.
In fact, the peak-to-peak fluctuation was only three digits $(0.000003 \mathrm{mV} / \mathrm{V})$ in all calibrations.

\subsubsection{Short-term drift}

The uncertainty due to the short-term drift of the torque transducer during pre- and post-calibrations (J1 and J2) was calculated by the following equation for the increasing torque:

$w_{\mathrm{dft}, \mathrm{i}}^{2}=\frac{1}{3}\left(\frac{\overline{S_{\mathrm{post}, \mathrm{i}}^{\prime}}-\overline{S_{\mathrm{pre}, \mathrm{i}}^{\prime}}}{2 \overline{S_{\mathrm{J}, \mathrm{i}}^{\prime}}}\right)^{2}$,

where $\overline{S_{\mathrm{J}, \mathrm{i}}^{\prime}}$ is the mean of $\overline{S_{\mathrm{pre}, \mathrm{i}}^{\prime}}$ and $\overline{S_{\text {post,i }}^{\prime}}$.

\subsubsection{Stability of the amplifier/indicators}

The relative standard uncertainty due to the stability of the amplifier/indicators was included as $w_{\text {amp }}$ by using the relative standard deviation in Table 2.

\subsubsection{Torque by using the TSMs}

From the description in Section 2, the relative standard uncertainties of realized torque by using the TSM $w_{\text {tsm }}$ are $1.7 \times$ $10^{-5}$ for $1-\mathrm{kN} \cdot \mathrm{m}-\mathrm{DWTSM}$ and $3.4 \times 10^{-5}$ for $20-\mathrm{kN} \cdot \mathrm{m}-\mathrm{DWTSM}$ at NMIJ and $2.5 \times 10^{-5}$ for $2-\mathrm{kN} \cdot \mathrm{m}-\mathrm{DW} T S M$ at KRISS with a coverage factor of $k=2$ (equivalent to a confidence level of approximately $95 \%$ ).

\subsubsection{Influence of temperature and humidity}

The standard uncertainties $u\left(\alpha_{\mathrm{t}}\right)$ or $u\left(\beta_{\mathrm{h}}\right)$ in Table 3 show just the uncertainty of the fitting curves (slopes). The units are $(\mathrm{mV} / \mathrm{V}) /{ }^{\circ} \mathrm{C}$ or $(\mathrm{mV} / \mathrm{V}) / \%$. The relative standard uncertainties $w_{\text {tmp }}$ and $w_{\text {hmd }}$ were calculated by using the following equations:

$w_{\mathrm{hmd}, \mathrm{i}}=\frac{u_{\mathrm{hmd}, \mathrm{i}}}{\overline{S_{\mathrm{i}}^{\prime}}}=\frac{1}{\overline{S_{\mathrm{i}}^{\prime}}} \sqrt{u^{2}\left(\left.\overline{S_{\mathrm{i}}^{\prime}}\right|_{\mathrm{h} 40}\right)+\Delta b^{2} \cdot u^{2}\left(\beta_{\mathrm{h}}\right)+\beta_{\mathrm{h}}{ }^{2} \cdot u^{2}(\Delta b)}$ and

$$
w_{\mathrm{tmp}, \mathrm{i}}=\frac{u_{\mathrm{tmp}, \mathrm{i}}}{\overline{S_{\mathrm{i}}^{\prime}}}=\frac{1}{\overline{S_{\mathrm{i}}^{\prime}}} \sqrt{u^{2}\left(\left.\overline{S_{\mathrm{i}}^{\prime}}\right|_{\mathrm{t} 23}\right)+\Delta t^{2} \cdot u^{2}\left(\alpha_{\mathrm{t}}\right)+\alpha_{\mathrm{t}}{ }^{2} \cdot u^{2}(\Delta t)},
$$


where $\Delta h$ and $\Delta t$ are the relative humidity and temperature deviations from the reference values of $40 \%$ and $23{ }^{\circ} \mathrm{C}$, respectively, $u\left(\left.\overline{S^{\prime}}\right|_{b 40}\right)$ and $u\left(\left.\overline{S_{\mathrm{i}}^{\prime}}\right|_{\mathrm{t} 23}\right)$ are just the measurement uncertainties obtained by the procedure in Section 4.2, and $\mathrm{u}(\Delta h)$ is $1.0 \%$ and $u(\Delta t)$ is $0.05 \mathrm{~K}$.

\subsubsection{Evaluation of En number}

The relative expanded uncertainty of the calibrations at NMIJ (denoted as the J1 and J2 calibrations) was calculated by the following equation:

$$
W_{\mathrm{J}, \mathrm{i}}=k \cdot w_{\mathrm{c}_{-} \mathrm{J}, \mathrm{i}}=k \cdot \sqrt{\frac{w_{\mathrm{rot}, \mathrm{i}}{ }^{2}+w_{\mathrm{rep}, \mathrm{i}}{ }^{2}+w_{\mathrm{zer}, \mathrm{i}}{ }^{2}+w_{\mathrm{res}, \mathrm{i}}{ }^{2}}{}}
$$

The relative expanded uncertainty of the calibration at KRISS (denoted as the $\mathrm{K}$ calibration) was calculated by the following equation:

$$
W_{\mathrm{K}, \mathrm{i}}=k \cdot w_{\mathrm{c} \_\mathrm{K}, \mathrm{i}}=k \cdot \sqrt{\frac{w_{\mathrm{rot}, \mathrm{i}}{ }^{2}+w_{\mathrm{rep}, \mathrm{i}}{ }^{2}+w_{\mathrm{zer}, \mathrm{i}}{ }^{2}+w_{\mathrm{res}, \mathrm{i}}{ }^{2}}{+w_{\mathrm{tsm}}{ }^{2}+w_{\mathrm{hmd}}{ }^{2}+w_{\mathrm{tmp}}{ }^{2}+w_{\mathrm{amp}}{ }^{2}}} .
$$

The $E_{\mathrm{n}}$ number was also evaluated according to the following equation:

$E_{\mathrm{n}, \mathrm{i}}=\frac{\left(\overline{S_{\mathrm{K}, \mathrm{i}}^{\prime}}-\overline{S_{\mathrm{J}, \mathrm{i}}^{\prime}}\right) / \overline{S_{\mathrm{J}, \mathrm{i}}^{\prime}}}{\sqrt{W_{\mathrm{K}, \mathrm{i}}{ }^{2}+W_{\mathrm{J}, \mathrm{i}}{ }^{2}}}$,

where $\overline{S_{K, i}^{\prime}}$ denotes the result of the calibration at KRISS.

Table 5 summarizes the results of the $E_{\mathrm{n}}$ number evaluation. The relative deviations and the total uncertainties are compared in the results obtained in the two NMIs in Figures 13(a)-13(h). These figures show the relative deviations of KRISS values from NMIJ values. The error bars express the relative expanded uncertainty of measurements obtained from (14) and (15). The $E_{\mathrm{n}}$ numbers were all less than unity in the calibration range from $50 \mathrm{~N} \cdot \mathrm{m}$ to $2 \mathrm{kN} \cdot \mathrm{m}$. Therefore, the equivalence of the torque standards between NMIJ and KRISS were confirmed.
However, the total measurement uncertainties became much larger than the CMCs of the two NMIs because the uncertainties of the corrections were added; in particular, a somewhat large influence occurred in the results having large differences of the relative humidity. It might arouse much controversy that the more corrections could be considered, the better the result of $E_{n}$ evaluation becomes, because the total uncertainty necessarily becomes larger than original value (see (16)). As an example of one of solutions for this problem, see the reference [9].

The steps of $500 \mathrm{~N} \cdot \mathrm{m}$ and $1000 \mathrm{~N} \cdot \mathrm{m}$ in this comparison coincide with those of CCM.T-K1 (one of the CIPM Key comparisons) [10]. A subject of future study will be to link the comparison results to CCM.T-K1.

\section{CONCLUSIONS}

An inter-laboratory comparison of the calibrations for torque measuring devices was conducted between NMIJ/AIST and KRISS in the range from $50 \mathrm{~N} \cdot \mathrm{m}$ to $2 \mathrm{kN} \cdot \mathrm{m}$. Both NMIs have well-established deadweight-type TSMs. In the calibration range from $50 \mathrm{~N} \cdot \mathrm{m}$ to $2 \mathrm{kN} \cdot \mathrm{m}$, the relative deviations were from $0.2 \times 10^{-5}$ to $2.4 \times 10^{-5}$. Sufficiently small deviations could be obtained between the calibration results of the two laboratories as contrasted with their CMCs, so the equivalence of the torque standards between NMIJ and KRISS was confirmed again. The influences of the stability and difference of voltage ratio spans in the amplifier/indicators as well as the temperature and humidity dependency of the transducer outputs could also be successfully evaluated.

\section{REFERENCES}

[1] Y. K. Park, M. S. Kim, J. H. Kim, J. H. Choi and D. I. Kim, "Establishment of torque standards in KRISS of Korea", Proc. 20th Int. Conf. IMEKO TC-3, Merida, 2007, CD-ROM.

[2] M. S. Kim and Y. K. Park, "Design of the $20 \mathrm{kN} \cdot \mathrm{m}$ Deadweight

\begin{tabular}{|c|c|c|c|c|c|c|c|c|}
\hline Direction & $\begin{array}{l}\text { Torque } \\
\text { in } \mathrm{N} \cdot \mathrm{m}\end{array}$ & $\begin{array}{c}\text { Cal. J } \\
\text { in } \mathrm{mV} / \mathrm{V}\end{array}$ & $\begin{array}{c}\text { Cal. } \mathrm{K} \\
\text { in } \mathrm{mV} / \mathrm{V}\end{array}$ & $\begin{array}{c}\text { Rel. Dev. } \\
\text { in } \%\end{array}$ & $\begin{array}{c}\text { S. T. Drift } \\
\text { in } \%\end{array}$ & $\begin{array}{c}U_{\mathrm{J}} \\
\text { in } \%\end{array}$ & $\begin{array}{c}U_{\mathrm{K}} \\
\text { in } \%\end{array}$ & $E_{\mathrm{n}}$ \\
\hline \multicolumn{9}{|l|}{$\mathrm{TN} / 2 \mathrm{kNm}$} \\
\hline \multirow{2}{*}{$\mathrm{CW}$} & 1000 & 0.751265 & 0.751260 & -0.0006 & -0.0017 & 0.0076 & 0.0064 & -0.06 \\
\hline & 2000 & 1.502633 & 1.502645 & 0.0008 & -0.0013 & 0.0071 & 0.0058 & 0.08 \\
\hline \multirow{2}{*}{$\mathrm{CCW}$} & -1000 & -0.751244 & -0.751233 & -0.0014 & -0.0013 & 0.0075 & 0.0062 & -0.14 \\
\hline & -2000 & -1.502522 & -1.502508 & -0.0010 & -0.0036 & 0.0072 & 0.0057 & -0.10 \\
\hline \multicolumn{9}{|l|}{ TB2/1kNm } \\
\hline \multirow{2}{*}{$\mathrm{CW}$} & 500 & 0.500185 & 0.500191 & 0.0012 & -0.0009 & 0.0046 & 0.0064 & 0.15 \\
\hline & 1000 & 1.000439 & 1.000448 & 0.0008 & -0.0008 & 0.0038 & 0.0060 & 0.12 \\
\hline \multirow{2}{*}{$\mathrm{CCW}$} & -500 & -0.500193 & -0.500182 & -0.0021 & -0.0011 & 0.0046 & 0.0063 & -0.27 \\
\hline & -1000 & -1.000467 & -1.000465 & -0.0002 & -0.0010 & 0.0038 & 0.0057 & -0.02 \\
\hline \multicolumn{9}{|c|}{ TN/100Nm(MD1) } \\
\hline \multirow{2}{*}{$\mathrm{CW}$} & 50 & 0.757805 & 0.757809 & 0.0006 & 0.0020 & 0.0048 & 0.0064 & 0.07 \\
\hline & 100 & 1.515693 & 1.515684 & -0.0006 & 0.0011 & 0.0040 & 0.0057 & -0.08 \\
\hline \multirow{2}{*}{$\mathrm{CCW}$} & -50 & -0.757807 & -0.757824 & 0.0024 & -0.0037 & 0.0049 & 0.0063 & 0.29 \\
\hline & -100 & -1.515706 & -1.515743 & 0.0024 & -0.0042 & 0.0044 & 0.0058 & 0.34 \\
\hline \multicolumn{9}{|c|}{$\mathrm{TN} / 100 \mathrm{Nm}(\mathrm{MD} 2)$} \\
\hline \multirow{2}{*}{$\mathrm{CW}$} & 50 & 0.755867 & 0.755877 & 0.0013 & 0.0000 & 0.0046 & 0.0067 & 0.16 \\
\hline & 100 & 1.511800 & 1.511815 & 0.0010 & -0.0003 & 0.0039 & 0.0058 & 0.15 \\
\hline \multirow{2}{*}{$\mathrm{CCW}$} & -50 & -0.755883 & -0.755894 & 0.0015 & -0.0008 & 0.0046 & 0.0073 & 0.18 \\
\hline & -100 & -1.511855 & -1.511872 & 0.0011 & -0.0011 & 0.0039 & 0.0062 & 0.15 \\
\hline
\end{tabular}
Torque Standard Machine", Proc. 22nd Int. Conf. IMEKO TC3, Cape Town, 2014, USB Flash Drive.

Table 5. $E_{\mathrm{n}}$ evaluation results. 


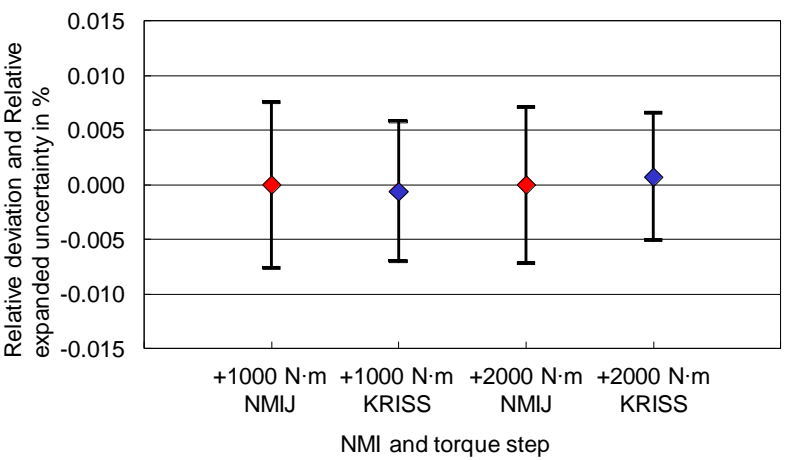

(a) $\mathrm{TN} / 2 \mathrm{kNm}, \mathrm{CW}$

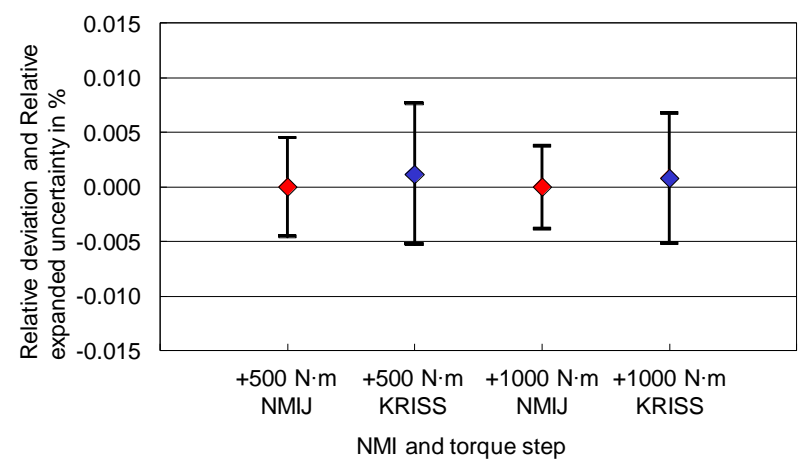

(c) $\mathrm{TB} 2 / 1 \mathrm{kNm}, \mathrm{CW}$

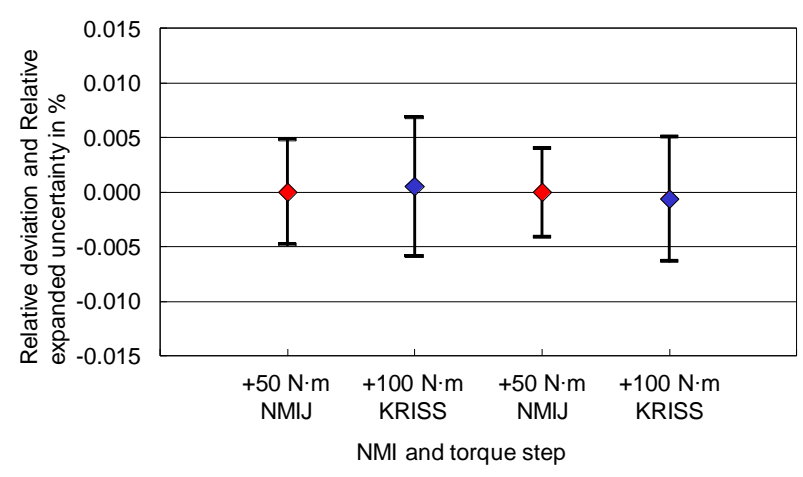

(e) TN/100Nm(MD1), CW

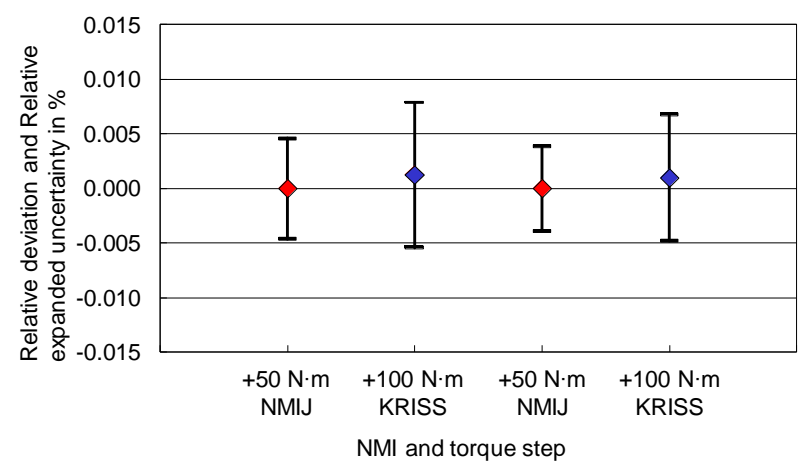

(g) TN/100Nm(MD2), CW

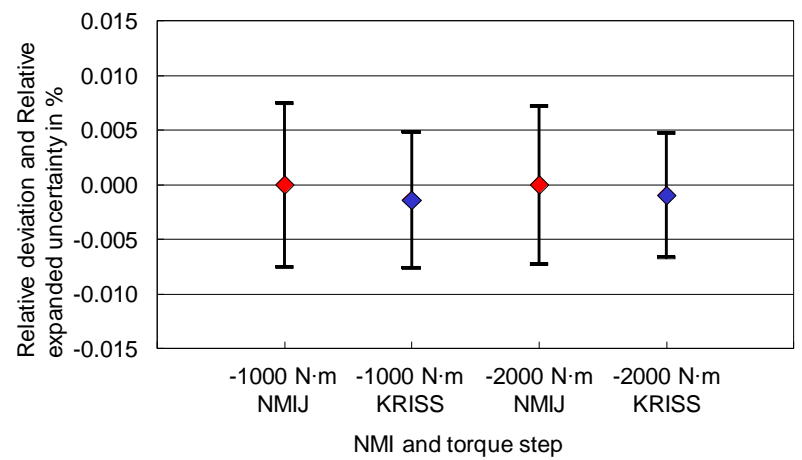

(b) $\mathrm{TN} / 2 \mathrm{kNm}, \mathrm{CCW}$

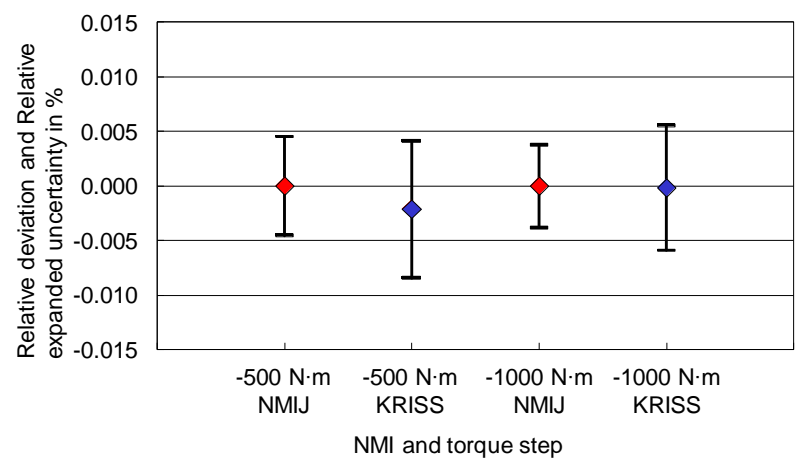

(d) $\mathrm{TB} 2 / 1 \mathrm{kNm}, \mathrm{CCW}$

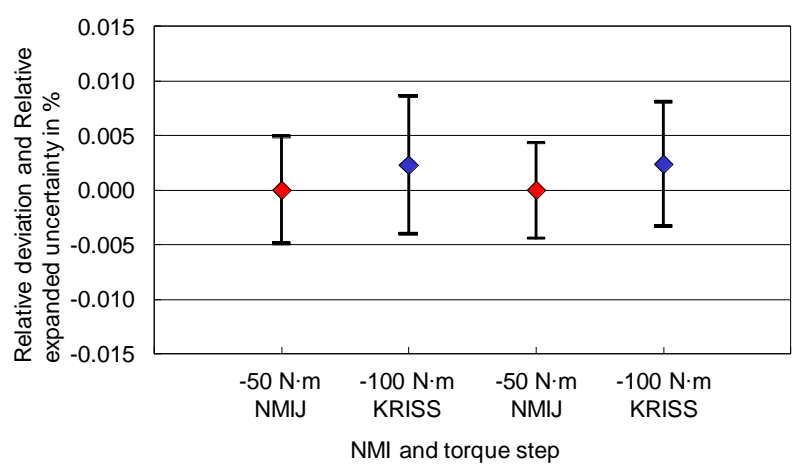

(f) TN/100Nm(MD1), CCW

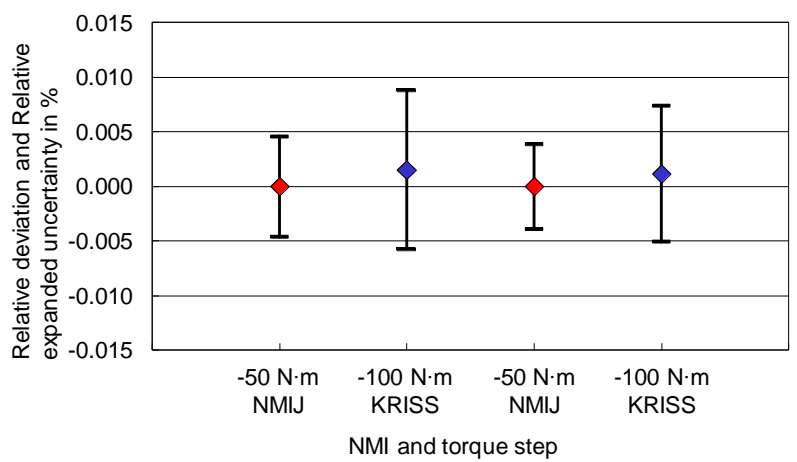

(h) TN/100Nm(MD2), CCW

Figure 13. Relative deviations and uncertainty of comparison calibration. 
[3] A. Nishino, K. Ogushi and K. Ueda, "Uncertainty evaluation of a $10 \mathrm{~N} \cdot \mathrm{m}$ dead weight torque standard machine and comparison with a $1 \mathrm{kN} \cdot \mathrm{m}$ dead weight torque standard machine", Measurement, 49, pp.77-90, 2014.

[4] K. Ohgushi, T. Tojo and E. Furuta, "Development of the 1 $\mathrm{kN} \cdot \mathrm{m}$ Torque Standard Machine", Proc. XVI IMEKO World Congress, Vol. 3, Vienna, 2000, pp.217-223.

[5] K. Ohgushi, T. Ota and K. Ueda, "Uncertainty Evaluation of the $20 \mathrm{kN} \cdot \mathrm{m}$ Deadweight Torque Standard Machine", Proc. 19th Int. Conf. IMEKO TC-3, Cairo, 2005, CD-ROM.

[6] K. Ohgushi, T. Ota, K. Ueda, Y. K. Park and M. S. Kim, "International Comparison of Torque Standards between the National Metrology Institute of Japan (NMIJ) and Korea Research Institute of Standards and Science (KRISS)", Proc. Asia-Pacific Symposium on Mass, Force and Torque (APMF), Jeju, 2005, CD-ROM
[7] K. Ohgushi, A. Nishino, T. Ota, K. Ueda, "Expansion of the calibration range and improvement of the uncertainty in the 1 $\mathrm{kN} \cdot \mathrm{m}$ deadweight torque standard machine", Proc. 20th Int. Conf. IMEKO TC-3, Merida, 2007, CD-ROM.

[8] D. Röske and K. Ogushi, "Final Report on the Torque Key Comparison CCM.T-K2 Measurand Torque: $0 \mathrm{kN} \cdot \mathrm{m}, 10 \mathrm{kN} \cdot \mathrm{m}$, $20 \mathrm{kN} \cdot \mathrm{m}$ ", Metrologia, 53, Technical Supplement 07008, 2016.

[9] D. Röske, "A German Torque Comparison from $20 \mathrm{~N} \cdot \mathrm{m}$ to 200 $\mathrm{N} \cdot \mathrm{m}$ and Its Results", Proc. 22th Int. Conf. IMEKO TC-3, Cape Town, 2014, http://www.imeko.org/publications/tc32014/IMEKO-TC3-2014-015.pdf.

[10] D. Röske, "Final Report on the Torque Key Comparison CCM.T-K1 Measurand Torque: $0 \mathrm{~N} \cdot \mathrm{m}, 500 \mathrm{~N} \cdot \mathrm{m}, 1000 \mathrm{~N} \cdot \mathrm{m}$ ", Internet:

http://www.bipm.org/utils/common/pdf/final reports/M/TK1/CCM.T-K1.pdf, 2009. 